\title{
The combination of oral quercetin supplementation and exercise prevents brain mitochondrial biogenesis
}

\author{
Rafael Antonio Casuso • Emilio José Martínez-López • Fidel Hita-Contreras • \\ Daniel Camiletti-Moiron · Rubén Martínez-Romero • Ana Cañuelo • \\ Antonio Martínez-Amat
}

Received: 22 April 2014/Accepted: 24 July 2014/Published online: 5 August 2014

(C) Springer-Verlag Berlin Heidelberg 2014

\begin{abstract}
The purpose of this study was to investigate whether the combination of oral quercetin $(\mathrm{Q})$ supplementation and exercise prevents mitochondrial biogenesis. Four groups of Wistar rats were tested: quercetin-sedentary (Qsedentary); quercetin-exercised (Q-exercised); no-quercetin-sedentary (NQ-sedentary); and no-quercetin-exercised (NQ-exercised). Treadmill exercise training took place 5 days a week for 6 weeks. Quercetin groups were supplemented with $25 \mathrm{mg} / \mathrm{kg}$ of quercetin throughout the experimental period. Sirtuin 1 (SIRT1), peroxisome-proliferator-activated receptor $\gamma$ coactivator-1 $\alpha$ (PGC-1 $\alpha$ ) mRNA levels and the activity of citrate synthase (CS) were measured in the brain. Redox status was also quantified by measuring the enzymatic activity of catalase (CAT) and superoxide dismutase (SOD) and protein carbonyls content (PCC). Q-Exercised $(P<0.001)$ and Q-sedentary $(P=0.042)$ groups increased PCC. In the Q-sedentary, there was an antioxidant enzymatic activity modulation for CAT $(P<0.001)$ and SOD $(P<0.01)$ but not in the
\end{abstract}

R. A. Casuso $(\bowtie) \cdot$ F. Hita-Contreras · A. Martínez-Amat Department of Health Sciences, University of Jaén, 23071 Jaén, Spain

e-mail: casusopt@gmail.com

E. J. Martínez-López

Department of Music, Plastic Expression and Body Language, University of Jaén, 23071 Jaén, Spain

D. Camiletti-Moiron

Department of Physiology, Institute of Nutrition and Food

Technology, School of Pharmacy, University of Granada,

Campus Universitario de Cartuja s/n, 18071 Granada, Spain

R. Martínez-Romero · A. Cañuelo

Department of Experimental Biology, University of Jaén,

23071 Jaén, Spain
Q-exercised. Q-sedentary showed a similar response to exercise in the brain by increasing CS activity in the brain $(P<0.01)$ and by activating the transcription of SIRT1 $(P<0.001)$ and PGC-1 $\alpha(P=0.03)$. These effects were hampered in the Q-exercised group. Quercetin is a prooxidant agent in the brain, but it modulates antioxidant activity in a sedentary condition. Quercetin supplementation during exercise compromises mitochondrial biogenesis induced separately by quercetin and exercise.

Keywords Quercetin - Exercise - Brain - Mitochondria · Redox status

\section{Introduction}

Regular exercise has many beneficial effects: Exercise maintains brain health, also improves the cognitive processes and increases resistance in order to prevent brain injury (Griesbach et al. 2004; Radák et al. 2001). Until recently, the significance of the brain in relation to its inclusion within investigations that focused on exercise adaptations was actually very minimal. Nevertheless recently, it has been demonstrated that exercise induces similar mitochondrial adaptations in the brain and in skeletal muscle (Steiner et al. 2011). In the brain, exercise increases mitochondrial content by a transcriptional regulation of peroxisome-proliferator-activated receptor $\gamma$ coactivator-1 $\alpha$ (PGC-1 $\alpha)$ and sirtuin 1 (SIRT1) (Steiner et al. 2011).

Quercetin $\left(3,3^{\prime}, 4^{\prime}, 5,7\right.$-pentahydroxyflavone) is a natural polyphenolic flavonoid which is present in significant amounts; in onions, garlic, leeks, cabbages, apples, blueberries, tea and red wine (Manach et al. 2004). Quercetin increases mitochondrial content by activating the 
transcription of SIRT1 and PGC-1 $\alpha$ in skeletal muscle (Davis et al. 2009). This fact leads our research team to test whether these muscular adaptations which are induced by quercetin actually enhance mitochondrial adaptations that are triggered by exercise. However, we found that when supplemented during exercise, quercetin hampers exerciseinduced mitochondrial biogenesis and increases oxidative stress (Casuso et al. 2013a). This is explained because when an exercise protocol begins, there is an oxidative stress which can be sustained by the cell in order to achieve adaptations (Powers and Jackson 2008). However, quercetin metabolites are known to produce additional oxidative stress (Boots et al. 2005, 2007); thus, the combination of exercise and quercetin may exceed the oxidative challenge which can be tolerated by the cell.

In the brain, before homeostasis is achieved, exercise increases oxidative stress (Radák et al. 2007), similar to what has been described in skeletal muscle (Powers and Jackson 2008). Polyphenols in general (Kim et al. 2007; Lagouge et al. 2006) exert powerful biological activity in the brain. But quercetin is described as increasing mitochondrial content in the brain (Davis et al. 2009) in a similar way to exercise training (Steiner et al. 2011). The concomitant effect of quercetin and exercise may exceed the ability of the system to induce adaptations in the brain. Thus, it is important to test the hypothesis that quercetin supplementation during exercise will increase brain oxidative damage and may blunt exercise-induced adaptations in brain mitochondrial biogenesis, as it has been previously described for skeletal muscle. The aim of the present study was to test the effect of quercetin on the SIRT1-PGC-1 $\alpha$ transcription pathway, mitochondrial content and oxidative status in the brain of exercised rats.

\section{Methods}

Animals

This study was performed on male Wistar rats (6 weeks old). The animals were maintained for 8 weeks in individual cages under standard conditions of light and temperature and allowed ad libitum access to food (Harlan 2014, maintenance chow) and water. All experiments were approved by the Committee for Ethics of the University of Jaén (Spain).

\section{Exercise and supplementation}

Rats were randomly assigned to quercetin $(\mathrm{Q} ; n=17)$ and no-quercetin (NQ; $n=16$ ) groups. Both groups were further divided into Q-exercised $(n=9)$, Q-sedentary $(n=8)$, NQ-exercised $(n=8)$ and NQ-sedentary $(n=8)$.
All rats were acclimated to experimental conditions for 2 weeks and 3 days before the 6-week training period, and trained groups were acclimated to the treadmill. Treadmill training took place 5 days a week for 6 weeks (five rats Panlab Treadmills for LE 8710R). The rats ran at a constant speed of $44 \mathrm{~cm} / \mathrm{s}$ at an angle of $10^{\circ}$. The rats ran for 20 min during the first 2 days and for $25 \mathrm{~min}$ on the third day. Training duration increased by 5 min every 2 days.

The rats ran for $80 \mathrm{~min}$ on the last day of the fifth week and also throughout the last week of training (Casuso et al. $2013 b$ ). The rats in the supplemented groups were supplemented with quercetin, via gavage, (QU995; Quercegen Pharma, Newton, MA) on alternate days throughout the experimental period. A dose of $25 \mathrm{mg} / \mathrm{kg}$ diluted in a $1 \%$ solution of methylcellulose was used. The quercetin dosage and length were chosen because in a preliminary study, we found a $<2.5$-fold increase in plasma quercetin levels. The no-quercetin groups were also supplemented, using the gavage procedure, with the vehicle (1\% solution of methylcellulose).

\section{Tissue collection}

All rats were anesthetized with pentobarbital and were bled by the cannulation of the aorta $48 \mathrm{~h}$ after the final exercise. The brains were immediately collected, rinsed in saline solution, frozen in liquid nitrogen, and then stored at $-80{ }^{\circ} \mathrm{C}$ until they needed to be further analyzed.

\section{Quantitative RT-PCR}

Gene expression of different genes [peroxisome-proliferator-activated receptor $\gamma$ coactivator 1, PGC-1; $\mathrm{NAD}(+)$-dependent histone deacetylases, SIRT-1] was quantitatively assessed by real-time PCR using $\beta$-actin as the normalizing gene. Total RNA was isolated from cell extracts using Trizol reagent (Invitrogen) according to the manufacturer's instructions. After treatment with DNase, cDNA was synthesized from $1.5 \mu \mathrm{g}$ total RNA using reverse transcriptase (SuperscriptTM III RT, Invitrogen) with oligo-(dT) 15 primers (Promega). Real-time PCR was performed on the Stratagene MxPro 3005P qPCR system using the Brilliant II SyBR Green QPCR Master Mix (STRATAGENE, La Jolla, CA, USA). The following primer pairs were used: PGC-1 $\alpha, 5^{\prime}$-GCGGACAGAACTGAGAGACC-3' and 5'-CGACCTGCGTAAAGTATATCCA3'; SIRT-1, 5'-CCTGACTTCAGATCAAGAGATGGTA-3 ${ }^{\prime}$ and $5^{\prime}$-CTGATTAAAAATATCTCCACGAACAG-3 ${ }^{\prime} ; \beta$ actin, 5' CTTAGAAGCATTTGCGGTGCCGATG-3' ${ }^{\prime}$ and 5'-TCATGAAGTGTGACGTTGCATCCGT-3'. Experiments were performed with triplicates, and the relative quantities of target genes corrected with the normalizing gene, $\beta$-actin, were calculated using the STRATAGENE 
MxProTM QPCR Software. Quantification of mRNA expression of PGC- $1 \alpha$ and SIRT-1 was calculated using the $\Delta \Delta \mathrm{CT}$ method as previously described (Livak and Schmittgen 2001).

\section{Mitochondrial DNA quantification}

DNA (mitochondrial and nuclear) was extracted from the cerebral cortex using a QIAamp DNA minikit (QIAGEN, Chatsworth, CA), and the concentration of each sample was determined spectrophotometrically at $260 \mathrm{~nm}$. Realtime PCR was performed on the Stratagene MxPro 3005P qPCR system using the Brilliant II SyBR Green QPCR Master Mix (STRATAGENE, La Jolla, CA, USA). Mitochondrial content was estimated as the ratio between copy numbers of mtDNA (cytochrome b; forward, 5'-AAAGCC ACCTTGACCCGATT-3'; reverse, 5'-GATTCGTAGGGC CGCGATA-3'; probe, 5'-CGCTTTCCACTTCATCTTAC CATT- $\left.3^{\prime}\right)$ versus nuclear DNA ( $\beta$-actin).

Thiobarbituric acid reactive substances

Thiobarbituric acid reactive substances (TBARS), major indicators of oxidative stress, were determined in mice brain following the instructions of the Oxikek TBARS Assay Kit (ZeptoMetrix Corp.). Final values were referred to the total protein concentration in the initial extracts.

Protein carbonyls

Determination of the protein carbonyl contents, an indicator of oxidative stress, was analyzed by 2,4-dinitrophenylhydrazine method as described by Levine et al. (1990). Results were expressed as $\mathrm{mmol} / \mathrm{mg}$ protein.

\section{Enzyme assays}

For catalase (CAT) activity, the cerebral cortex from animals was dissected, rinsed in saline solution and stored at $-80{ }^{\circ} \mathrm{C}$ until used. Cerebral cortices were homogenized on ice in $5-10 \mathrm{ml}$ of cold buffer $(50 \mathrm{mM}$ potassium phosphate, $\mathrm{pH} 7.0$, containing $1 \mathrm{mM}$ EDTA) per gram of tissue. After centrifugation at $10,000 \times g$ for $15 \mathrm{~min}$, the supernatants were collected for protein determination (Bradford 1976) and subsequent analysis. All the procedures were performed at $4{ }^{\circ} \mathrm{C}$. CAT activity was studied by monitoring the decomposition of $\mathrm{H} 2 \mathrm{O} 2$ at $240 \mathrm{~nm}$, according to the method described by Beers and Sizer (1952). For superoxide dismutase (SOD) activity, the cerebral cortices were homogenized on ice in $5-10 \mathrm{ml}$ of cold buffer $(20 \mathrm{mM}$ HEPES, pH 7.2, containing $1 \mathrm{mM}$ EGTA, $210 \mathrm{mM}$ mannitol and $70 \mathrm{mM}$ sucrose) per gram tissue. After centrifugation at $15,000 \times g$ for $5 \mathrm{~min}$, the supernatant was collected for protein determination (Bradford 1976) and subsequent analysis. All the procedures were performed at $4{ }^{\circ} \mathrm{C}$. SOD activity was assayed by measuring the rate of inhibition of cytochrome $\mathrm{c}$ reduction by superoxide anions generated by a xanthine/xanthine oxidase system (Flohé and Ötting 1984).

Total citrate synthase (CS) activity was measured in Tris- $\mathrm{HCl}$ buffer $(50 \mathrm{mM}$ Tris- $\mathrm{HCl}, 2 \mathrm{mM}$ EDTA and $250 \mu \mathrm{M}$ NADH $\mathrm{pH} 7.0$ ) and $0.04 \%$ Triton-X. The CS reaction was started by the addition of $10 \mathrm{mM}$ oxaloacetate, and activity was measured spectrophotometrically by measuring the disappearance of NADH at $412 \mathrm{~nm}$. Total protein content of all homogenates was determined by the method of Bradford (1976).

\section{Statistics}

Results are presented as mean \pm SD. Homoscedasticity and normality were tested by Levene and KolmogorovSmirnov test, respectively. Results were analyzed using two-factor ANOVA (with/without quercetin and with/ without exercise). If this analysis revealed a significant interaction, specific differences between mean values were located using Student's $t$ test for independent samples. $t$ test for independent samples was performed to analyze final weight, distance ran and food intake. The level of significance was considered at $P<0.05$. All the analyses were performed using the Statistical Package for Social Sciences (SPSS, version 19.0 for Windows; SPSS, Inc., Chicago, IL, USA).

\section{Results}

Exercise, food intake and body weight

NQ-exercised $(1,040 \pm 83 \mathrm{~m})$ and Q-exercised $(1,021 \pm$ $60 \mathrm{~m})$ ran the same average amount of meters over the trained period $(P>0.05)$. Q-exercised $(22.41 \pm 2.05 \mathrm{~g})$ and NQ-exercised $(21.17 \pm 1.22 \mathrm{~g})$ had higher average food intake $(P<0.001)$ than the not-exercised groups (18.47 \pm 1.44 for Q-sedentary and $17.28 \pm 1.46$ for NQsedentary). Final weight did not differ between groups.

Effect of quercetin and exercise on brain CAT and SOD activity

Quercetin modulated brain antioxidant activity (Fig. 1), in fact, in Q-sedentary CAT $(16.68 \pm 0.3 \mathrm{mmol} / \mathrm{mg}$ protein; $P<0.001)$ and SOD $(8.02 \pm 0.2 \mathrm{mmol} / \mathrm{mg}$ protein; $P<0.01)$ increased when compared to the NQ-sedentary group $(9.44 \pm 1.1$ and $4.81 \pm 0.6 \mathrm{mmol} / \mathrm{mg}$ protein for CAT and SOD, respectively). This effect was, however, 

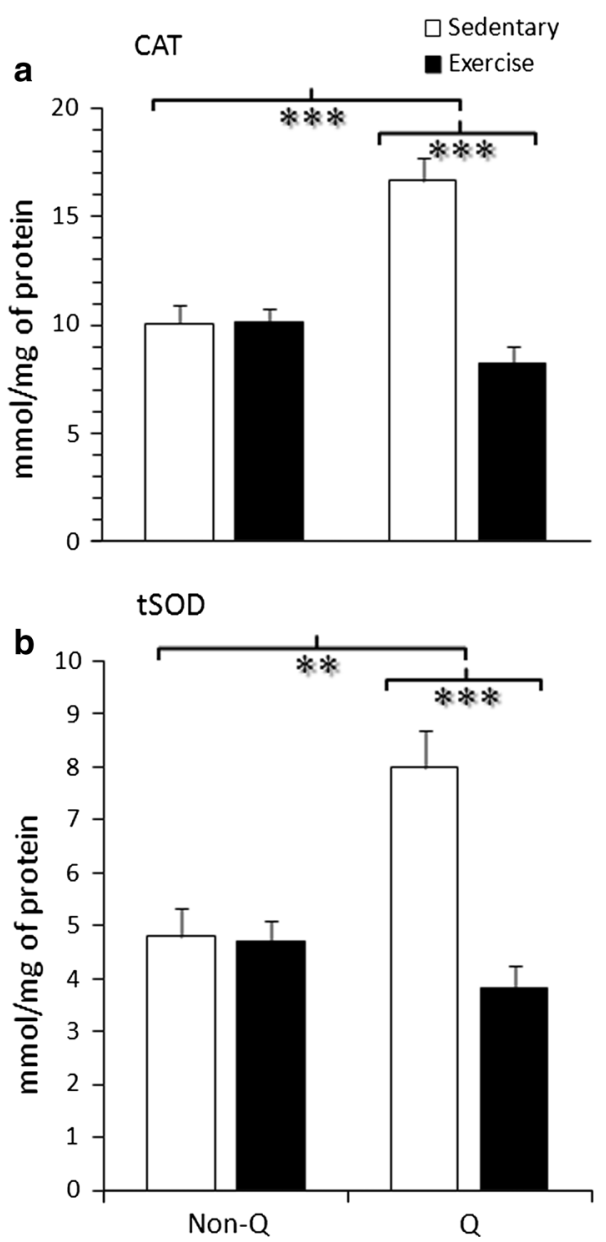

Fig. 1 Effects of quercetin supplementation and exercise on CAT (a) and total SOD (b) activity in brain. Values are mean \pm SD. Results for two-factor ANOVA (with/without quercetin and with/ without exercise) and Student's $t$ test for independent sample, when interaction was significant. $* * P<0.01$ and $* * * P<0.001$

abolished in the Q-exercised for CAT $(8.31 \pm 1.85 \mathrm{mmol} /$ $\mathrm{mg}$ protein; $P<0.001)$ and SOD $(3.87 \pm 0.8 \mathrm{mmol} / \mathrm{mg}$ protein; $P<0.001)$. Exercise decreased CAT and SOD activities $(P<0.001$, main effect for exercise $)$.

Effect of exercise and quercetin on brain lipid and protein oxidative damage

Exercise decreased TBARS in brain $(P=0.001$; main effect for exercise; Fig. 2a). Moreover, exercise reduced PCC $(P<0.05 ; \quad$ Fig. $2 b)$ in the NQ-exercised $(13.91 \pm 4.54 \mathrm{mmol} / \mathrm{mg}$ protein) compared with the NQsedentary $(17.07 \pm 0.79 \mathrm{mmol} / \mathrm{mg}$ protein). Quercetin showed higher $(P=0.042)$ PCC in the Q-sedentary $(22.33 \pm 0.3 \mathrm{mmol} / \mathrm{mg}$ protein) than in the NQ-sedentary. Regarding the exercised groups, the Q-exercised
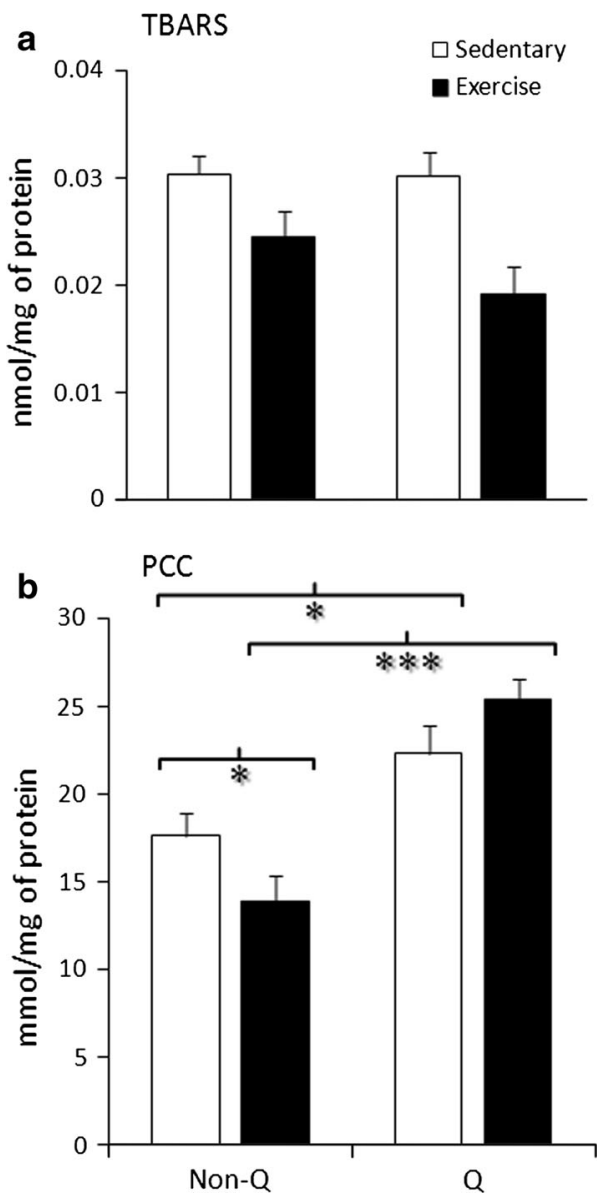

Fig. 2 Effects of quercetin supplementation and exercise on TBARS (a) and protein carbonyls content (PCC) (b) in brain. Values are mean \pm SD. Results for two-way ANOVA (with/without quercetin and with/without exercise) and Student's $t$ test for independent sample, when interaction was significant. $* P<0.05$ and $* * * P<0.001$

$(25.29 \pm 2.6 \mathrm{mmol} / \mathrm{mg}$ protein) showed a robust increase $(P<0.001)$ in PCC when compared to NQ-exercised.

Effect of exercise and quercetin on brain SIRT1 and PGC- $1 \alpha$ mRNA levels

Relative induction of PGC- $1 \alpha$ and SIRT1 in the brain is shown in Fig. 3. Regarding the NQ-exercised group, there was an increased SIRT1 $(1.81 \pm 0.31 ; P<0.001)$ and PGC-1 $\alpha(1.15 \pm 0.2 ; P<0.01)$ when compared to the control group. Likewise, there was a transcriptional activation in the Q-sedentary of SIRT1 $(2.74 \pm 0.42$; $P<0.01)$ and PGC- $1 \alpha(0.95 \pm 0.18 ; P<0.01)$. The Q-exercised group showed a lower relative induction of SIRT1 $(0.50 \pm 0.09)$ than the NQ-exercised $(P<0.01)$ and the Q-sedentary $(P<0.01)$. Furthermore, the 

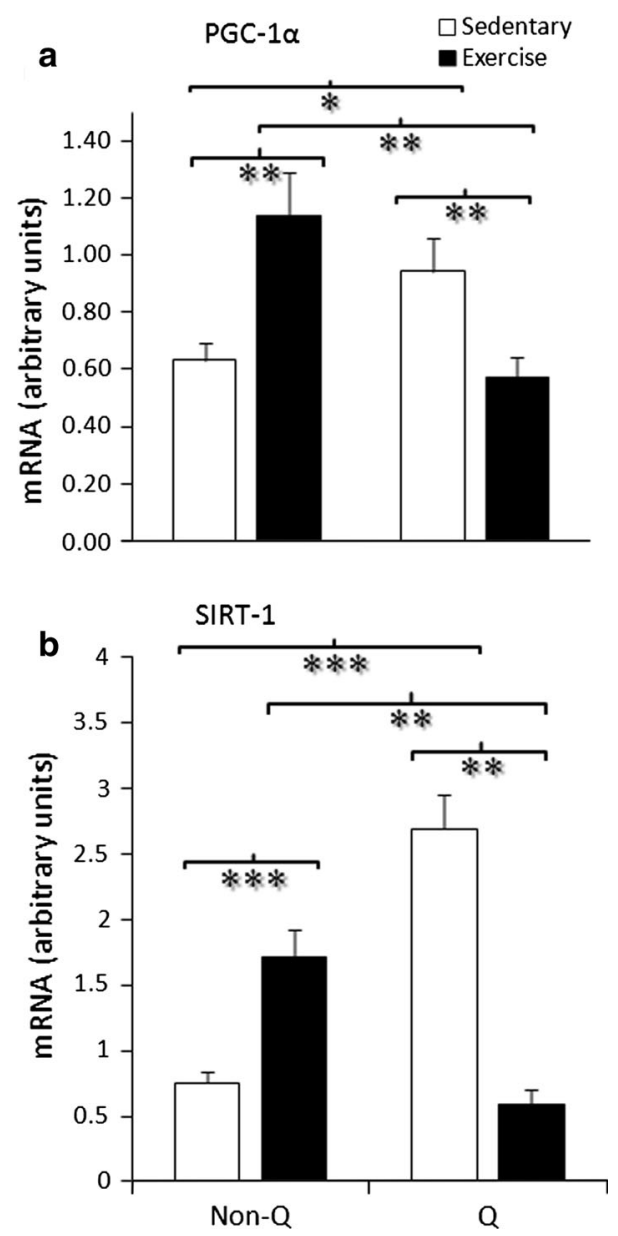

Fig. 3 Effects of quercetin supplementation and exercise on PGC- $1 \alpha$ and SIRT1 expression in brain. Values are mean \pm SD. Results for two-way ANOVA (with/without quercetin and with/without exercise) and Student's $t$ test for independent sample, when interaction was significant. $* P<0.05, * * P<0.01$ and $* * * P<0.001$

Q-exercised showed a lower PGC-1 $\alpha(0.58 \pm 0.04)$ when compared with Q-sedentary $(P<0.01)$ and NQ-exercised $(P<0.01)$.

Effect of exercise and quercetin on brain mitochondrial DNA content and CS activity

Markers of mitochondrial content in the brain are shown in Fig. 4. Exercise training increased CS activity $(26.25 \pm 3.88 ; \quad P<0.001)$ and mtDNA $(1.9 \pm 0.27$; $P<0.001)$ as shown for the NQ-exercised when compared to NQ-sedentary $(14.38 \pm 4.03$ for CS and $1.0 \pm 0.21$ for mtDNA). Likewise, quercetin exerted a similar effect on CS activity $(24.5 \pm 5.2 ; \quad P<0.01)$ and mtDNA $(1.8 \pm 0.15 ; P<0.001)$ when the Q-sedentary was compared with NQ-sedentary. Quercetin supplementation during exercise hampered these effects induced separately by quercetin and exercise. In fact, the Q-exercised group
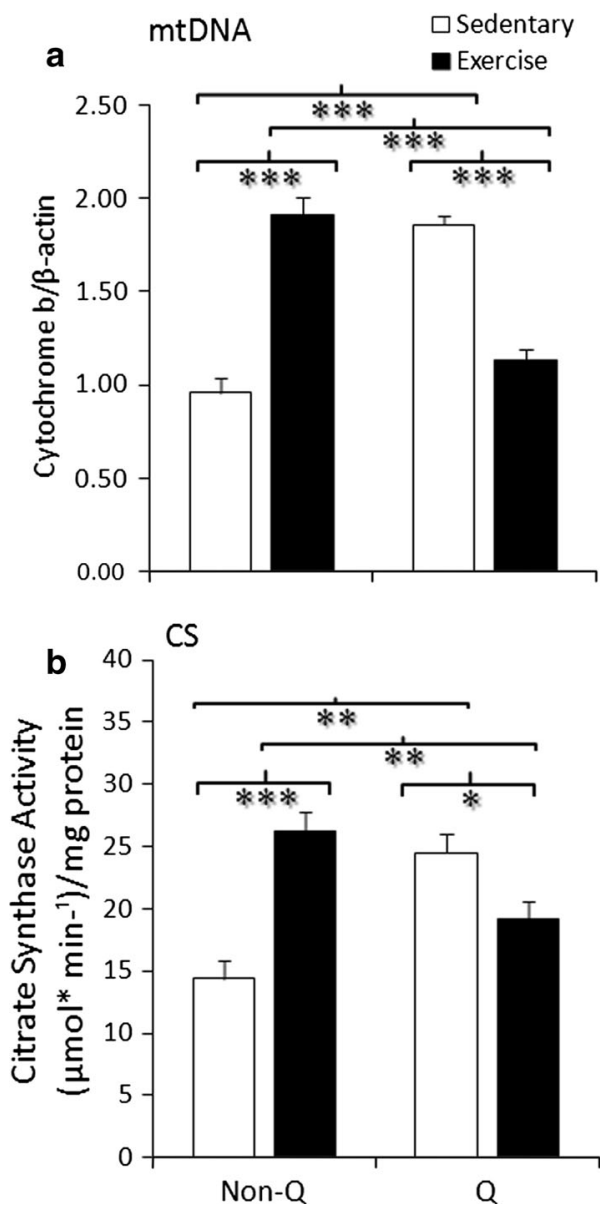

Fig. 4 Effects of quercetin supplementation and exercise on mitochondrial DNA content and CS activity. Values are mean \pm SD. Results for two-way ANOVA (with/without quercetin and with/ without exercise) and Student's $t$ test for independent sample, when interaction was significant. $* P<0.05, * * P<0.01$ and $* * * P<0.001$

showed a lower mtDNA $(1.1 \pm 0.2)$ content when compared with both the NQ-exercised $(P<0.001)$ and the Q-sedentary $(P<0.001)$. Furthermore, when quercetin was supplemented during exercise, there is a blunted activity of CS $(19.11 \pm 6.8)$ in comparison with NQexercised $(P<0.01)$ and Q-sedentary $(P<0.05)$.

\section{Discussion}

In the present study, we used a rat model to study the effects of quercetin and exercise on both the brain redox status and mitochondrial content. Quercetin supplementation without exercise increased mitochondrial biogenesis via up-regulation of the PGC- $1 \alpha$ and SIRT- 1 pathway. We also found that the combination of quercetin with exercise decreased exercise-induced mitochondrial adaptations in the brain through a down-modulation of the PGC- $1 \alpha$ and SIRT1 pathway also increasing the amount of oxidative 
markers. It must be highlighted that the dose of quercetin used is quite high and, in order to reach this quantity, a $80-\mathrm{kg}$ person should consume around $1 \mathrm{~kg}$ of onions (the richest source of quercetin).

Once ingested, quercetin shows a quite extensive metabolism and it can be absorbed by the stomach (Crespy et al. 2002), but most quercetin is absorbed from the small intestine (Manach et al. 2004; Spencer 2007). In food, quercetin is present in the glycosylated forms being glucose the most frequent sugar moiety, although other sugars may also be involved. Flavonoids in general and quercetin in particular undergo an extensive phase I and phase II metabolism (Rendeiro et al. 2012). Phase I consists in deglycosylation (Spencer et al. 2004), and phase II consists of the metabolism of the resulting aglycones to glucuronides, sulfates and O-methylated forms during transfer across the small intestine (Spencer et al. 1999; 2000). Quercetin is able to cross blood-brain barrier and in fact, O-methylated forms of quercetin are accumulated in significant amount in both neurons and astrocytes. (Spencer et al. 2004).

The brain is not usually considered when exercise adaptations are studied. Inactivity, however, is a risk factor for many chronic disorders, regardless of age, gender, race or health status. In fact, in relation to neurological disorders, possible clinical consequences of inactivity are as follows: learning and memory impairment, cognitive dysfunction, dementia, depression, mood and anxiety disorders and neurodegeneration (Handschin and Spiegelman 2008). Some of these neurological disorders, if not all, can be counteracted by regular moderate intensity exercise by an up-regulation of the PGC-1 $\alpha$ gene (Handschin and Spiegelman 2008). In fact, a recent study has proved that endurance exercise increases brain mitochondrial biogenesis by increasing the transcription of the SIRT1-PGC- $1 \alpha$ pathway (Steiner et al. 2011). Accordingly, our results suggest that 6 weeks of exercise training increases brain mitochondrial content through the transcription of both SIRT1 and PGC-1 $\alpha$.

Quercetin, a natural polyphenolic flavonoid present in a variety of plant foods (Manach et al. 2004), is supposed to mimic exercise-induced up-regulation of the SIRT1-PGC$1 \alpha$ pathway and mitochondrial biogenesis in the brain (Davis et al. 2009). Our data support this statement, because we have found that quercetin increases brain mitochondrial content through the activation of the SIRT1PGC- $1 \alpha$ pathway. PGC- $1 \alpha$ is considered the main regulator of mitochondrial biogenesis, because it interacts and co-activates some transcription factors such as peroxisome-proliferator-activated receptors (PPARs), estrogenrelated receptors (ERRs) and nuclear respiratory factors, NRF-1 and NRF-2, that govern most of mitochondrial functions and biogenesis (Scarpulla et al. 2012). In the brain, SIRT1 seems to galvanize PGC-1 $\alpha$ at the transcriptional level (Steiner et al. 2011). The SIRT1-PGC$1 \alpha$ interaction is well described in scientific literature; SIRT1 is a metabolic sensor induced by NAD + in situations of energy/nutrient stress (Houtkooper et al. 2010). It is an important functional regulator of PGC- $1 \alpha$ by deacetylation in skeletal muscle (Gerhart-Hines et al. 2007) and, similarly, in brain tissue (Rodgers et al. 2008). Studies on mice treated with resveratrol (a polyphenol with a similar structure to quercetin) showed an expression of SIRT1, which correlated with deacetylation of PGC-1 $\alpha$, in the hippocampus (Kim et al. 2007; Lagouge et al. 2006). Although we did not measure protein content, our results indicate that 6-week quercetin supplementation increased mitochondrial content in the brain similarly to what has been previously reported after 7 days of supplementation in mice (Davis et al. 2009). What is more regarding mitochondrial biogenesis quercetin seems to mimic the effects that exercise has on the brain.

However, quercetin supplementation during exercise compromises both the exercise and quercetin effects on brain mitochondrial content by disrupting the SIRT1-PGC$1 \alpha$ pathway. This is in accordance with a previous result by our research team which concluded that quercetin supplementation during exercise abolishes exercise-induced effects on mitochondrial content by decreasing SIRT1 transcription (Casuso et al. 2013a). Moreover, our results are in accordance with the hypothesis that quercetin supplementation provides a disadvantage for adaptive responses to exercise-induced stress (Kuennen et al. 2011).

Similar to the conclusion of an elegant review (Radák et al. 2007), exercise training is likely to increase brain resistance and tolerance against oxidative stress. Both TBARS and PCC are decreased after 6 weeks of exercise training in brain tissue. Quercetin, however, induces higher amounts of protein carbonyls, suggesting brain oxidative damage was promoted by quercetin. The pro-oxidant effect of quercetin was previously named as the "Quercetin Paradox" (Boots et al. 2005) because during its antioxidant effect, some quercetin metabolites formed turn to prooxidant agents (Boots et al. 2007). It should be noted that in the Q-sedentary group, there is an increased activity of some antioxidant enzymes which suggest a self-protection effect against oxidative damage. However, this enzymatic up-regulation is hampered in the Q-exercised group. Physical activity is a brain stressor, at least, at the early stage of exercise training, when a high amount of ROS is produced and the adaptation has not been achieved (Radák et al. 2007). Given that oxidative stress is thought to link metabolic health and mitochondrial physiology (Ristow and Schmeisser 2011), it is possible that the blunted mitochondrial adaptation found in the Q-exercised group is due to the impossibility of the cell to assimilate oxidative challenge. 
Finally, it is necessary to compare our results with data on other antioxidants such as vitamin $\mathrm{C}$ and vitamin $\mathrm{E}$. It is difficult to assess antioxidant administration during exercise because results usually differ probably due to differences in the methodologies used (Nikolaidis et al. 2012). Nevertheless, our results are similar to those reported by Coskun et al. (2005), reporting that vitamin C supplementation during exercise increases brain oxidative damage. Furthermore, when vitamin $\mathrm{C}$ is supplemented during exercise, it hampers mitochondrial biogenesis (GomezCabrera et al. 2008) and metabolic adaptations (Ristow et al. 2009) induced by exercise.

\section{Conclusions}

The primary conclusion of the present study is that quercetin impedes exercise-induced adaptations in the brain. Quercetin induces oxidative damage which, in the sedentary condition, is counteracted by modulating antioxidant activity. Moreover, in the Q-sedentary group, there is an increased transcription of SIRT1 and PGC- $1 \alpha$ resulting in a higher mitochondrial content, in a similar way than exercise. These mitochondrial adaptations are hampered if quercetin is supplemented during exercise. However, the present study has a limitation that should be mentioned, because protein content of SIRT1 and PGC-1 $1 \alpha$ was not measured. Thus, our results should be applied at the transcriptional level and do not extend to assessing protein levels. Nevertheless, future research should be focused in elucidating the physiological pathway of quercetin in the brain in health and disease.

Acknowledgments The authors gratefully acknowledge all the members of Department of Physiology (School of Pharmacy and Institute of Nutrition and Food Technology, University of Granada, Spain) for their collaboration and Quercegen Pharma for kindly providing quercetin used in the study. The present study was partially funded by the Master of Physical Activity and Health Sciences (University of Jaén, Spain).

Conflict of interest Rafael A. Casuso, Emilio Martínez-López, Fidel Hita-Contreras, Daniel Camiletti-Moiron, Rubén Martínez-Romero, Ana Cañuelo and Antonio Martínez-Amat declare that they have no conflict of interest.

Ethical standard All institutional and national guidelines for the care and use of laboratory animals were followed.

\section{References}

Beers KF Jr, Sizer IW (1952) A spectrophotometric method of measuring the breakdown of hydrogen peroxide by catalase. J Biol Chem 195:133-139

Boots AW, Balk JM, Bast A, Haenen GR (2005) The reversibility of the glutathionyl-quercetin adduct spreads oxidized quercetininduced toxicity. Biochem Biophys Res Commun 338:923-929
Boots AW, Li H, Schins RP, Duffin R, Heemskerk JW, Bast A, Haenen GR (2007) The quercetin paradox. Toxicol Appl Pharmacol 222:89-96

Bradford MM (1976) A rapid and sensitive method for the quantification of microgram quantities of protein utilizing the principle of protein-dye binding. Anal Biochem 72:248-254

Casuso RA, Martínez-Amat A, Martínez-López EJ, Camiletti-Moirón D, Porres JM, Aranda P (2013a) Ergogenic effects of quercetin supplementation in trained rats. J Int Soc Sports Nutr 10:3

Casuso RA, Martínez-López EJ, Nordsborg NB, Hita-Contreras F, Martínez-Romero R, Cañuelo A, Martínez-Amat A (2013b) Oral quercetin supplementation hampers skeletal muscle adaptations in response to exercise training. Scand J Med Scien Sports Exerc In press

Coşkun S, Gönül B, Güzel NA, Balabanlí B (2005) The effects of vitamin $\mathrm{C}$ supplementation on oxidative stress and antioxidant content in the brains of chronically exercised rats. Mol Cell Biochem 280:135-138

Crespy V, Morand C, Besson C, Manach C, Demigne C, Remesy C (2002) Quercetin, but not its glycosides, is absorbed from the rat stomach. J Agric Food Chem 50:618-621

Davis JM, Murphy EA, Carmichael MD, Davis B (2009) Quercetin increases brain and muscle mitochondrial biogenesis and exercise tolerance. Am J Physiol Regul Integr Comp Physiol 296:R1071-R1077

Flohé L, Ötting F (1984) Superoxide dismutase assays. Methods Enzymol 105:93-104

Gerhart-Hines Z, Rodgers JT, Bare O, Lerin C, Kim SH, Mostoslavsky R, Alt FW, Wu F, Puigserver P (2007) Metabolic control of muscle mitochondrial function and fatty acid oxidation through SIRT1/PGC-1alpha. EMBO J 26:1913-1923

Gomez-Cabrera MC, Domenech E, Romagnoli M, Arduini A, Borras C, Pallardo FV, Sastre J, Viña J (2008) Oral administration of vitamin $\mathrm{C}$ decreases muscle mitochondrial biogenesis and hampers training-induced adaptations in endurance performance. Am J Clin Nutr 87:142-149

Griesbach GS, Hovda DA, Molteni R, Wu A, Gomez-Pinilla F (2004) Voluntary exercise following traumatic brain injury: brainderived neurotrophic factor upregulation and recovery of function. Neuroscience 125:129-139

Handschin C, Spiegelman BM (2008) The role of exercise and PGC1alpha in inflammation and chronic disease. Nature 454:463-469

Houtkooper RH, Cantó C, Wanders RJ, Auwerx J (2010) The secret life of NAD + : an old metabolite controlling new metabolic signaling pathways. Endocr Rev 31:194-223

Kim D, Nguyen MD, Dobbin MM, Fischer A, Sananbenesi F, Rodgers JT, Delalle I, Baur JA, Sul G, Amour SM, Puigserver P, Sinclair DA, Tsai LH (2007) SIRT1 deacetylase protects against neurodegeneration in models for Alzheimer's disease and amyotrophic lateral sclerosis. EMBO J 26:3169-3179

Kuennen M, Gillum T, Dokladny K, Bederick E, Schenider S, Moseley P (2011) Thermotolerance and heat acclimation may share a common mechanism in humans. Am J Physiol Regul Integr Comp Physiol 301:R524-R533

Lagouge M, Argmann C, Gerhart-Hines Z, Meziane H, Lerin C, Daussin F, Messadeq N, Milne J, Lambert P, Elliot P, Geny B, Laakso M, Puigserver P, Auwerx J (2006) Resveratrol improves mitochondrial function and protects against metabolic disease by activating SIRT1 and PGC-1alpha. Cell 127:1109-1122

Levine RL, Garland D, Oliver CN, Amici A, Climent L, Lenz AG, Ahn BW, Shaltiel S, Stadtman ER (1990) Determination of carbonyl content in oxidatively modified proteins. Methods Enzymol 186:464-478

Livak KJ, Schmittgen TD (2001) Analysis of relative gene expression data using real-time quantitative PCR and the 2(-Delta Delta C(T)) Method. Methods 25:402-408 
Manach C, Scalbert A, Morand C, Rémésy C, Jiménez L (2004) Polyphenols: food sources and bioavailability. Am J Clin Nutr 79:727-747

Nikolaidis MG, Kerksick CM, Lamprecht M, McAnulty SR (2012) Does vitamin $\mathrm{C}$ and $\mathrm{E}$ supplementation impair the favorable adaptations of regular exercise? Oxid Med Cell Longev 2012:707941

Powers SK, Jackson MJ (2008) Exercise-induced oxidative stress: cellular mechanisms and impact on muscle force production. Physiol Rev 88:1243-1276

Radák Z, Kaneko T, Tahara S, Nakamoto H, Pucksok J, Sasvári M, Nyakas C, Goto S (2001) Regular exercise improves cognitive function and decreases oxidative damage in rat brain. Neurochem Int 38:17-23

Radák Z, Kumagai S, Taylor AW, Naito H, Goto S (2007) Effects of exercise on brain function: role of free radicals. Appl Physiol Nutr Metab 32:942-946

Rendeiro C, Guerreiro JD, Williams CM, Spencer JP (2012) Flavonoids as modulators of memory and learning: molecular interactions resulting in behavioural effects. Proc Nutr Soc 71:246-262

Ristow M, Schmeisser S (2011) Extending life span by increasing oxidative stress. Free Rad Biol Med 51:327-336

Ristow M, Zarse K, Oberbach A, Klöting N, Birringer M, Kiehntopf M, Stumvoll M, Kahn CR, Blüher M (2009) Antioxidants prevent health-promoting effects of physical exercise in humans. Proc Natl Acad Sci USA 106:8665-8670

Rodgers JT, Lerin C, Gerhart-Hines Z, Puigserver P (2008) Metabolic adaptations through the PGC- $1 \alpha$ and SIRT1 pathways. FEBS Lett 582:46-53

Scarpulla RC, Vega RB, Kelly DP (2012) Transcriptional integration of mitochondrial biogenesis. Trends Endocrinol Metab 23:459-466

Spencer JP (2007) The interactions of flavonoids within neuronal signalling pathways. Genes Nutr 2:257-273

Spencer JP, Chowrimootoo G, Choudhury R, Debnam ES, Srai SK, Rice-Evans C (1999) The small intestine can both absorb and glucuronidate luminal flavonoids. FEBS Lett 458:224-230

Spencer JP, Chaudry F, Pannala AS, Srai SK, Debnam E, Rice-Evans C (2000) Decomposition of cocoa procyanidins in the gastric milieu. Biochem Biophys Res Commun 272:236-241

Spencer JP, Abd-el-Mohsen MM, Rice-Evans C (2004) Cellular uptake and metabolism of flavonoids and their metabolites: implications for their bioactivity. Arch Biochem Biophys 423:148-161

Steiner JL, Murphy EA, McClellan JL, Carmichael MD, Davis JM (2011) Exercise training increases mitochondrial biogenesis in the brain. J Appl Physiol 111:1066-1071 